\title{
Solutions to Peto's Paradoxes and to Wright's Enigma have Implications for Cancer Prevention.
}

\author{
Naseema-Maria Begum ${ }^{1}$, James A Morris ${ }^{2 *}$ \\ ${ }^{1}$ Department of Pathology, Royal Lancaster Infirmary, UK \\ ${ }^{2}$ Faculty of Health \& Medicine, Lancaster University, UK
}

Submission: February 06, 2017; Published: February 28, 2017

*Corresponding author: James A Morris, Department of Pathology, Royal Lancaster Infirmary, UK, Emaill: Jim.A.Morris@mbht.nhs.uk

\begin{abstract}
The conventional view of carcinogenesis, based on over 50 years of theoretical and experimental research, is that the chance accumulation of a specific set of somatic mutations in a single stem cell leads to a monoclonal malignant tumour. Somatic mutation is increased by exposure to external mutagens but still occurs in their absence. Thus, although causative agents, such as smoking, can be identified, cancer will still occur even if conditions are ideal. This conventional idea, however falls foul of Peto's paradoxes and of Wright's enigma. Men are a thousand times larger than mice and live thirty times as long; they should have a markedly increased rate of malignancy compared with mice but they do not (Peto's paradox). Furthermore many gastro-intestinal tumours are oligoclonal, not monoclonal at inception (Wright's enigma). The solution to the paradoxes is to reject the conventional view that stem cells cycle every few days throughout life and accept instead the hierarchical model of stem cell genesis. The latter model predicts that the number of cell divisions between the zygote and differentiated cells (r) is less than 60 in men as long as the hierarchy is maintained. Cancer will only occur if the orderly progression of the hierarchy is disturbed and $r$ is increased. Factors which can disturb the hierarchy include ulceration, inflammation, trauma and viral infection. Cancers have a cause and cancer prevention is possible.
\end{abstract}

Keywords: Peto's paradox; Wright's enigma; Carcinogenesis; Hierarchical model of stem cell genesis; Breast cancer; Lymphoma; Cancer prevention

\section{Introduction}

Cancer is due to the accumulation of deleterious mutations in stem cells. If a single stem cell acquires a specific set of $\mathrm{m}$ mutations leading to loss of growth control then the cell will proliferate to form a monoclonal malignant neoplasm, in which all the malignant cells are ultimately derived from the single aberrant stem cell. This concept, which has become the central dogma of carcinogenesis, is the result of over 50 years of theoretical and experimental work in cancer research.

Epidemiologists in the 1960s and 1970s noted that most common cancers increased in prevalence as a power function of age [1-6]: Prevalence of cancer being proportional to age raised to the power $n$, where $\mathrm{n}$ has values close to 7 . Incidence, which is the first derivative of prevalence, is therefore proportional to age raised to the power $n-1$.

The power function is consistent with the concept of multiple hits leading to cancer and it was postulated that the hits were equivalent to deleterious mutations. Thus the simplest model is that the accumulation of $\mathrm{n}$ specific mutations in a single stem cell leads to cancer. But more complex models were soon proposed. One possibility is that cancer develops in stages, with initial mutations leading to clonal expansion and then subsequent mutations leading to cancer. In this case the number of mutations for malignancy (m) might be less than $\mathrm{n}$. A second possibility is that the genome becomes progressively more unstable as mutations accumulate and in this case the value of $\mathrm{m}$ could be greater than $n$.

Laboratory based experimental work in the 1980s and 1990s confirmed the prescient predictions of the above theoretical models [7-10]. Oncogenes, which switch on growth, are kept in check by anti-oncogenes and by other tumour suppressive mechanisms. Thus it requires at least two deleterious mutations in one cell before uncontrolled growth occurs. Retinoblastoma is due to two mutations disabling both retinoblastoma genes and leading to the loss of the retinoblastoma gene transcription protein. But there are far more stem cells, and stem cell mitoses, in the colon, for instance, than in the retina, and colon cancer would be far more common than observed if only two deleterious 
mutations were sufficient for cancer to occur. Thus in practice it is likely that $\mathrm{m}$ is closer to 4 than 2 for most of the common cancers [11-13].

\section{Peto's paradoxes}

Richard Peto wrote a review of multi-stage models of carcinogenesis in 1977 [5]. This article has recently been republished in a more accessible form [6]. In the article he noted two paradoxes.

The first is the man-mouse paradox. Men are one thousand times larger than mice and live 30 times as long. According to multi-stage models the prevalence of cancer in men should be vastly greater than in mice. The increase predicted by the models is $30^{\mathrm{m}} \times 1000$. If $\mathrm{m}=4$, the increase would be nearly a billion-fold. In fact the prevalence of cancer in men and mice is similar rising to comparable levels at the end of their respective lifespan $[14,15]$.

The second paradox is rather more subtle. Cancer rises as at least the fourth power of age but less than the second power of carcinogen dose. But multi-stage models predict the power of age and carcinogen dose should be the same. Peto states $[5,6]$ "The fact that the exponent of dose rate is so much lower than the exponent of time is one of the most important observations about the induction of carcinomas, and everyone should be familiar with it - and slightly puzzled by it!". We agree with this statement but would delete the word "slightly".

It is the second paradox that was originally termed Peto's paradox [15], but in recent years the term has also been applied to the first [16-18]. The solution to the paradoxes depends on stem cell kinetics. The number of mutations in stem cells and in fully differentiated cells depends on the mutation rate per cell division and the number of divisions that separate the stem cell or mature cell from the zygote. In a human lifetime approximately $7 \times 10^{15}$ mature differentiated cells are produced. The minimum number of cell divisions to produce this many cells is 53 . The number of cells produced in a lifetime by a mouse is closer to $2 \times 10^{11}$. This number of cells can be produced by 37 cell divisions. Thus the mutant frequency in fully differentiated cells in mice and men will be similar at the end of their natural lifespan, and thus the risk of cancer per cell will also be similar. But men have 1000 times more cells than mice and therefore this argument reduces the disparity in cancer rates from a billion fold to a thousand fold.

A similar argument can be applied to whales. They are a thousand fold larger than men and produce perhaps a thousand fold more cells. This would require approximately 63 cell divisions. Thus mutant frequency in men and whales will be similar and it will vary only two fold between whales and mice. The number of cells in whales, however, will be a million fold more than in mice.
The argument so far depends on the assumption that the stem cell hierarchy is strictly controlled and differentiated cells are never more than the minimum number of cell divisions from the zygote. This model of stem cell generation has been described previously $[15,19,20]$. It is different than the conventional model which assumes stem cells cycle regularly, every few days, and undergo up to several thousand divisions in a human lifetime. It is the conventional model that falls foul of Peto's paradox [20].

There is, however, still a thousand-fold disparity between men and mice and a million-fold disparity between whales and mice to explain. The answer to this comes from consideration of the red cell paradox. Each day humans produce 200 billion red cells, 100 billion neutrophils and 50 billion of all other cells. There are more mitotic divisions in the red cell series than in all other cells put together. If cancer depended on the number of stem cells then erythroleukaemia would be the commonest malignancy, in fact it is vanishingly rare. The conclusion to draw is that as long as there is strict control of the stem cell hierarchy and the number of cell divisions is kept to the minimum then malignancy, in practice, will not occur [20].

\section{Wright's enigma}

Professor Sir Nicholas Wright's group in London has shown, in a series of publications [21-25], that many tumours in the gastro-intestinal tract arise from more than one stem cell. The individual clones of these oligoclonal or polyclonal tumours compete, and in a process that mimics Darwinian selection, only one clone survives to become a monoclonal malignant tumour. This concept also challenges the conventional view of carcinogenesis.

It appears that fields of stem cells have mutation hot spots and it is in those focal areas that several stem cells acquire the $\mathrm{m}$ specific mutations for malignancy. Elsewhere, in the field the risk of a stem cell acquiring the m specific mutations is sufficiently low that cancer, in practice, does not occur.

This leads to the concept that the vast majority of stem cells in mice, men and whales have a mutation rate which is so low that they will not accumulate the specific set of m mutations in a lifetime regardless of their size and regardless of the length of their life. But in specific areas, due to a specific cause, the stem cells suffer a much higher mutation load and they can generate multiple malignant clones.

\section{Stem cell kinetics}

The solution to Wright's enigma and Peto's paradoxes depends on a consideration of stem cell kinetics $[15,19,20]$ (Table 1).

If stem cells cycle daily or every few days, as in the conventional model of stem cell genesis, then by late middle age $r$ will be a large number. It will not then be possible for the mutant frequency in the hot spots to be several multiplies of the 
mutant frequency of the rest of the stem cells. But if $r$ is less than 60 , as in the hierarchical model, the stem cells in the hot spots could go from 60 to say 600 in just two years and the mutant frequency could rise ten-fold. A ten-fold rise in mutant frequency Table 1: The hierarchical model of stem cell genesis in humans.

\begin{tabular}{|c|c|}
\hline Generation (r) & \\
\hline$r=0$ & The zygote \\
\hline$r=30$ to 45 & $\begin{array}{c}\text { These are the quiescent stem cells. Generation } 45 \text { is quiescent for one or two days only, but } \\
\text { generation } 44 \text { is quiescent for twice as long i.e. } 2 \text { to } 4 \text { days. Generation } 43 \text { is quiescent for } 4 \text { to } 8 \\
\text { days and so on so that the earliest stem cells are quiescent for many years. Generations } 40 \text { to } 45 \text { are } \\
\text { probably present in the anatomical niches that they create but generations } 30 \text { to } 40 \text { are likely to be in } \\
\text { the bone marrow. }\end{array}$ \\
\hline$r=45$ to 55 & $\begin{array}{l}\text { These are actively dividing stem cells that over a few days produce } 256,512 \text { or perhaps } 1024 \text { fully } \\
\text { differentiated cells that occupy the anatomical niche for a varying number of days depending on the } \\
\text { site. }\end{array}$ \\
\hline$r=55$ to 60 & These are fully differentiated cells. \\
\hline$r=60$ to 600 & $\begin{array}{c}\text { These are actively dividing abnormal stem cells in which the orderly progression of the stem cell } \\
\text { hierarchy has been lost. They acquire a high mutational load due to genetic instability and the nuclei } \\
\text { show varying degrees of dysplasia. Most of the cells will die due to the mutational load but a few } \\
\text { will form malignant clones that proliferate out of control. Most of the malignant clones will also die } \\
\text { due to the mutational load but rarely one will survive long enough to become a clinically recognized } \\
\text { malignant tumour. }\end{array}$ \\
\hline$r=100$ to 600 & $\begin{array}{c}\text { These are the cells of clinically recognized malignant tumours. The tumour cells show marked nuclear } \\
\text { pleomorphism. Continued division in the presence of a high mutational load and genetic instability } \\
\text { means that growth potential is limited and only some tumours will survive long enough to cause } \\
\text { death of the host. }\end{array}$ \\
\hline
\end{tabular}

Let q equal the mutation rate per cell division (this is of the order of $5 \times 10^{-10}$ per base pair per mitosis or $10^{-6}$ per gene per cell division).

Let $r$ equal the number of cell divisions from the zygote.

The mutant frequency in stem cells is then qr (the much lower mutation rate in cells during the quiescent phase is ignored).

\section{Cancer causation}

Focal inflammation can damage and destroy stem cells and if the orderly progression of the hierarchy is disturbed then dysplasia and malignancy could follow. This is seen in Barrett's glandular mucosa, when recurrent ulceration of the lower oesophagus, induced by reflux of acid and pepsin from the stomach, leads to dysplasia and then malignancy [26]. This can occur in the absence of mutagens although smoking does increase the risk. Helicobacter pylori infestation of the distal gastric mucosa also causes inflammation and increases the risk of gastric cancer and lymphoma [27]. Autoimmune mediated gastric atrophy in patients with pernicious anaemia predisposes to gastric adenocarcinoma and is another example of inflammation induced malignancy.

Adenocarcinoma of the colon is much more common than adenocarcinoma of the small intestine even though the small intestine has more stem cells than the colon. This has always been a problem for conventional models of stem cell genesis, but is explicable in terms of bacterial induced inflammation of the colonic mucosa. In particular patients with ulcerative colitis have an increased risk of colonic cancer [28]. with $m=4$ would raise the risk of malignancy ten thousand times. This model implies that the cause of cancer is loss of control of the stem cell hierarchy and the accumulation of the mutations for malignancy is secondary to this. 
Each year we all suffer several episodes of upper respiratory tract infection. Most of the viruses grow in the differentiated cells of the respiratory mucosa, induce cell lysis and then are released to infect others. But a few viruses have a more complicated life cycle. They grow in the differentiated respiratory cells and then have a second growth phase in circulating blood lymphocytes. Finally they enter the cells, including stem cells, of epithelia throughout the body. The viruses can obviously cause genetic change in lymphocytes and in epithelial stem cells. This is a plausible primary cause for lymphoma/leukemia and for carcinoma in many tissues including the breast.

\section{Implications for prevention}

If cancer at specific sites has a specific cause, or a number of specific causes, then cancer prevention is a possibility. However, in patients born with deleterious mutations in the zygote which predispose to cancer, progression to malignancy at some sites might be inevitable in spite of preventive methods. But with this one exception the future for prevention is bright.

Bacterial induced inflammation of the colon, for instance, is theoretically preventable. We need to identify the specific bacteria that induce inflammation and replace them by less pathogenic close relations that will occupy the same ecological niche. There are hundreds of bacterial species that are found in the colon with many variants per species. We anticipate that the optimum flora will be identified in the not too distant future and developed and maintained by daily consumption of enteric coated bacterial containing pills. This should prevent ulcerative colitis as well as colonic cancer [31].

Immunization against HPV is likely to reduce the risk of squamous cell carcinoma of the cervix. Other viral induced neoplasms might well be prevented if we can identify the causative agents. The total viral load over a lifetime is likely to be a factor and efforts to reduce this by controlled low dose exposure by the respiratory and oral routes have been described previously [31]. Exposure to viruses and bacteria is inevitable, what we must learn to do is to engineer exposure such that the dose, the route and the timing is optimal so as to induce immunity with minimal damage.

Breast cancer is the commonest malignant tumour in females. A field change in stem cells leading to ductal carcinoma in situ is often present as the precursor of invasion. The model proposed in this paper would predict a causative agent which is focal, affecting some stem cells more than others and not a diffuse change affecting all cells equally. Trauma is one possibility, as already mentioned [30]. But viral carriage by the breast cells is perhaps more likely. Lactation is an obvious way of passing on viruses accumulated over the preceding years. It is also interesting to reflect that women who have an early lactation have a reduced risk of cancer. Women who never lactate have an increased risk $[32,33]$. Elimination of the viral particles early gives less chance for them to induce genetic change in the stem cells. This idea can be investigated by sequencing DNA and RNA in first lactation breast milk to see which viruses are commonly present.

A key target for prevention is smoking which is the main cause of lung cancer. A causative role for tobacco smoke has always seemed biologically plausible because it is a mutagen. Burning the leaves of the tobacco plant, however, releases thousands of biologically active molecules, many of which blunt the inflammatory response to infection [34]. Therefore the link between smoking and cancer might also involve inflammation and infection.

\section{Discussion}

Sir Richard Peto's article on multi-stage models of carcinogenesis, first published in 1977 [5] and now available on-line [6], repays careful study. Not only were the two, now eponymous, paradoxes presented but there was also prescient discussion of other key theoretical issues. These include the potential importance of the number of cell divisions separating differentiated cells from the zygote, and the possible oligoclonal origin of tumours. In effect a preview of the hierarchical model of stem cell genesis and of Wright's enigma.

The conventional view of carcinogenesis falls foul of Peto's paradoxes and of Wright's enigma [20]. If stem cells cycle every few days throughout life then cancer would be vastly more common in men than in mice, but it is not. If the number of stem cells in a tissue was the major determinant of cancer risk, as recently suggested by Tomasetti \& Volgenstein [35], then erythroleukaemia would be the commonest human malignancy, but it is not. If cancer is purely the product of the random accumulation of mutations in stem cells then tumours would not be oligoclonal at inception, but sometimes they are [21-25].

The problem with the conventional view of carcinogenesis is not the key idea that the accumulation of a specific set of mutations in a single stem cell leads to cancer. The problem is with the conventional view of stem cell kinetics. The hierarchical model of stem cell genesis proposes that the number of cell divisions separating differentiated cells in old age is close to the minimum number which is $\log _{2} \mathrm{~N}$ (where $\mathrm{N}$ is the total number of differentiated cells produced in a human lifetime) $[15,19,20]$. This model vastly reduces the risk of malignancy and in practice cancer would be rare in mice, men and whales so long as the orderly progression of the stem cell hierarchy is maintained. One exception, however, applies in those who have cancer predisposing mutations in the germ line. The chance of acquiring m-1 mutations in a stem cell is vastly greater than the chance of acquiring m mutations and could occur within 60 cell divisions.

The idea that carcinogens are mutagens has also had a powerful influence. Tobacco smoke, radiation and viral infection are all mutagens which increase the risk of cancer in many 
tissues. Mutagens increase the mutation rate per cell division and therefore increase the mutant frequency in stem cells. If the mutant frequency doubles and $m=4$ then the risk of a monoclonal malignant tumour arising will increase sixteen-fold [15]. But even heavy smokers are extremely unlikely to develop erythroleukaemia; thus smoking is mutagenic but it does not seem to be carcinogenic in practice for the majority of stem cells in the body. Perhaps tobacco smoke is acting predominantly on developing epithelial cells at the body's periphery rather than centrally on the bone marrow. But if so then the mutation rate will only rise in divisions 45 to 55 (Table 1). This will obviously have less effect on the mutant frequency than if all divisions from the zygote had been affected [36]. The model proposed in this paper is that merely increasing mutant frequency will not in itself lead to a monoclonal malignant tumour. What is required is a field change in a group of stem cells leading to loss of the orderly progression of the hierarchy. Mutagens, however, can cause cell death and they can produce mutations in the genes which are involved in control of the stem cell hierarchy. Indeed the combination of inflammation leading to stem cell loss combined with exposure to a mutagen such as tobacco smoke could be a potent force for damaging the stem cell hierarchy. An interaction of this type is seen in the development of adenocarcinoma from Barrett's glandular mucosa [26].

Dysplastic cells are oligoclonal and show evidence of genetic instability in the form of nuclear pleomorphism. According to the model presented in the table they are in excess of 60 divisions from the zygote. The work of Professor Wright's group indicates that a number of malignant clones are likely to develop but the majority will not survive. It is an inevitable property of an asexual growth that the growth potential will be limited by the accumulation of mutations [37,38]. The same principle will apply to any clinically apparent monoclonal malignant tumour that develops. Unfortunately all too often the tumour is capable of killing the host before the growth potential is exceeded. The process by which one clone emerges to become the monoclonal tumour has been compared with Darwinian selection. But rather than survival of the fittest, the term survival of the least decrepit might be more appropriate. Biological cells that have genetic instability and are accumulating mutations will have a limited lifespan. A therapeutic approach based on clearing the cells until the growth limit is reached might have some merit. This could be more successful than the current approach of tailoring therapy to the specific mutations found in the tumour cells. Clinically apparent malignant tumours contain billions of cells and every possible genetic mutation will be present in every tumour. Resistance to chemotherapy is therefore inevitable.

The best approach, however, is to prevent cancer arising in the first place. Solutions to Peto's paradoxes and to Wright's enigma indicate that this should be possible because each cancer has a cause other than random chance. Ulceration, inflammation, trauma and viral infection are all possible causative factors, acting to destroy stem cells and leading to loss of control of the stem cell hierarchy. What we need to do is to identify the cause or causes for each tumour type and then to develop preventive strategies. Immunization against the human papilloma virus (HPV) is a good example of how this could be achieved. Viruses also play a role in some cases of lymphoma and could be involved in most. We will never prevent all viral infection, but we could reduce the dose by controlling exposure and thereby reduce the total mutagenic effect [31].

The ideas developed in this paper are relevant in particular to breast cancer, the commonest cancer in women. Many viruses multiply in the body and then spread to epithelial cells before they are shed to the exterior. The breast is an obvious site for passing on viruses but they must reside in the breast epithelial cells for years prior to the first lactation: thus the sooner the lactation the less the damage. It is now possible to investigate this idea directly by sequencing DNA and RNA in milk of the first lactation. Once again controlled low dose early mucosal exposure to the causative viruses could reduce the degree of stem cell damage.

A final paradox in relation to breast cancer is that the disease is more common in taller women, in other words prevalence varies by body size $[32,33,39]$. The temptation to attribute this directly to body size, however, must be resisted in view of everything written above. A better explanation, published previously, has been referred to as the empty set theory [40]. The number of deleterious mutations in the genome is a Poisson variable with a mean in single figures, probably 5 or 6 [41]. These deleterious mutations interact synergistically in large complex genetic networks to impair performance on a wide range of skills. Those at the bottom end of the Poisson distribution are lucky; they grow to be tall, healthy, intelligent adults [40-42]. They do well in life and rise up the social scale. But because they have few deleterious mutations in the genome they can acquire four more without stem cell death. Those at the other end of the Poisson distribution are not as tall, and not as healthy overall, but they do have one advantage in relation to cancer: their cells are more likely to die before they accumulate the four mutations for malignancy.

\section{References}

1. Armitage P, Doll R (1954) The age distribution of cancer and a multistage theory of carcinogenesis. Br J Cancer 8(1): 1-12.

2. Armitage P, Doll R (1957) A two-stage theory of carcinogenesis in relation to the age distribution of human cancer. Br J Cancer 11(2): 161-169.

3. Doll R (1971) The age distribution of cancer: implications for models of carcinogenesis. J R Stat Soc Ser A 134(2): 133-166.

4. Knudsen AG (1971) Mutation and cancer: statistical study of retinoblastoma. Proc Natl Acad Sci 68(4): 820-823.

5. Peto R (1977) Epidemiology, multistage models, and short term mutagenicity tests. In: Hiatt HH, Watson JD, Winsten JA (eds.), Origin of human cancer. Cold Spring Harbor NY: Cold Spring Harbor Laboratory pp. $1403-1428$. 
6. Peto R (2016) Epidemiology, multistage models, and short term mutagenicity tests. Int J Epidemiol 45(3): 621-637.

7. Paul J (1984) Oncogenes. J Pathol 143(1): 1-10.

8. Weiss RA, Marshall CJ (1984) Oncogenes. Lancet ii: 1138-1142.

9. Green AR, Wyke JA (1985) Anti-oncogenes: a sub-set of regulatory genes involved in carcinogenesis. Lancet 2(8453): 475-477.

10. Vogelstein B, Fearon ER, Hamilton SR, Kern SE, Preisinger AC, et al. (1988) Genetic alterations during colorectal tumour development. N Engl J Med 319(9): 525-532.

11. Morris JA (1989) A mutational theory of leukaemogenesis. J Clin Pathol 42(4): 337-340.

12. Morris JA (1990) Spontaneous mutation rate in retinoblastoma. J Clin Pathol 43(6): 496-498.

13. Morris JA (1991) A mutational model of carcinogenesis. Anticancer Res 11(5): 1725-1130.

14. Peto R (2015) Quantitative implications of the approximate irrelevance of mammalian body size and lifespan to cancer risk. Philos Trans R Soc Lond B Biol Sci 370(1673): 20150198.

15. Morris JA (1994) Stem cell kinetics and intestinal cancer. Anticancer Res 14(5A): 2073-2076.

16. Nagy JD, Victor EM, Cropper JH (2007) Why don't all whales have cancer? A novel hypothesis resolving Peto's paradox. Integ Comp Biol 47(2): 317-328.

17. Caulin AF, Maley CC (2011) Peto's paradox: evolution's prescription for cancer prevention. Trends Ecol Evol 26(4): 175-182.

18. Noble R, Kaltz O, Hochberg ME (2015) Peto's paradox and human cancers. Philos Trans R Soc Lond B 370(1673): 20150104.

19. Morris JA (1999) The kinetics of epithelial cell generation: its relevance to cancer and ageing. J Theor Biol 199(1): 87-95.

20. Morris JA (2014) The hierarchical model of stem cell genesis explains the man mouse paradox, Peto's paradox, the red cell paradox and Wright's enigma. Med Hypotheses 83(6): 713-717.

21. Novelli MR, Williamson JA, Tomlinson IP, Elia G, Hodgson SV, et al (1996) Polyclonal origin of colonic adenomas in an XO/XY patient with FAP. Science 272(5265): 1187-1190.

22. Garcia SB, Novelli M, Wright NA (2000) The clonal origin and clonal evolution of epithelial tumours. Int J Exp Pathol 81(2): 89-116.

23. Thirlwell C, Will OC, Domingo E, Graham TA, McDonald SA, et al. (2010) Clonality assessment and clonal ordering of individual neoplastic crypts shows polyclonality of colorectal adenomas. Gastroenterol 138(4): 1441-1454.

24. Zeki SS, Graham TA, Wright NA (2011) Stem cells and their implications for colorectal cancer. Nat Rev Gastroenterol Hepatol 8(2): 90-100.

25. Baker AM, Graham TA, Wright NA (2013) Pre-tumour clones, periodic selection and clonal interference in the origin and progression of gastrointestinal cancer: potential for biomarker development. J Pathol 229(4): 502-514.
26. Naini BV, Souza RF, Octze RD (2016) Barrett's esophagus: a comprehensive and contemporary review for pathologists. Am J Surg Pathol 40(5): e45-66.

27. Choi YJ, Kim N (2016) Gastric cancer and family history. Korean J Intern Med 31: 1042-1053.

28. Lennard-Jones JE, Melville DM, Morson BC, Ritchie JK, Williams CB (1990) Pre cancer and cancer in extensive ulcerative colitis: findings among 401 patients over 22 years. Gut 31(7): 800-806.

29. Walboomers JM, Jacobs MV, Manos MM, Bosch FX, Kummer JA, et al. (1999) Human papilloma virus is a necessary cause of invasive cervical cancer worldwide. J Pathol 189(1): 12-19.

30. Rigby JE, Morris JA, Lavelle J, Stewart M, Gatrell AC (2002) Can physical trauma cause cancer? European J Cancer Prevention 11(3): 307-311.

31. Morris JA, Harrison LM, Lauder RM, Telford DR, Neary R (2012) Low dose mucosal exposure will minimize the risk of microbial disease. Medical Hypotheses 79(5): 630-634.

32. Kelsey JL, Gammon MD, John EM (1993) Reproductive factors and Breast cancer. Epidemiol Rev 15(1): 36-47.

33. Lipworth L (1995) Epidemiology of breast cancer. Eur J Cancer Prev 4(1): 7-30.

34. Moscovis SM, Cox A, Hall ST, Burns CJ, Blackwell CC (2015) Effects of gender, cytokine polymorphisms and environmental factors on inflammatory responses. Innate Immun 21(5): 523-530.

35. Tomasetti C, Vogelstein B (2015) Variation in cancer risk among tissues can be explained by the number of stem cell divisions. Science 347(6217): 78-81.

36. Morris JA (1992) Low dose radiation and childhood cancer. J Clin Pathol 45(5): 378-381.

37. Morris JA, Morris RD (2003) The conservation of redundancy in genetic systems: the effects of sexual and asexual reproduction. J Biosci 28(60: 671-681.

38. Morris RD, Morris JA (2004) Sexual selection, redundancy and survival of the most beautiful. J Biosci 29(3): 359-366.

39. Warner ET, Hu R, Collins LC, Beck AH, Schnitt S, et al. (2016) Height and body size in childhood, adolescence, and young adulthood and breast cancer risk according to molecular subtype in the Nurses' Health Studies. Cancer Prev Res 9(9): 732-738.

40. Morris JA (1997) Genetic control of redundant systems. Med Hypotheses 49(2): 159-164.

41. Morris JA (2005) Synergistic interaction of heterozygous deletions impairs performance and confers susceptibility to disease at all ages. Med Hypotheses 65(3): 483-493.

42. Morris JA (1999) Information and redundancy: key concepts in understanding the genetic control of health and intelligence. Med Hypotheses 53(2): 118-123. 


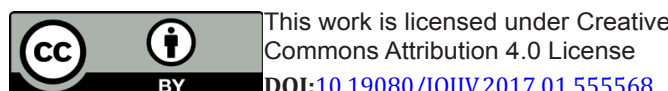

BY DOI:10.19080/JOJIV.2017.01.555568
Your next submission with Juniper Publishers will reach you the below assets

- Quality Editorial service

- Swift Peer Review

- Reprints availability

- E-prints Service

- Manuscript Podcast for convenient understanding

- Global attainment for your research

- Manuscript accessibility in different formats

( Pdf, E-pub, Full Text, Audio)

- Unceasing customer service

Track the below URL for one-step submission https://juniperpublishers.com/online-submission.php 